\title{
Mortality of patients with childhood onset (0-17 years) Type I diabetes in Israel: a population-based study*
}

\author{
T. Laron-Kenet ${ }^{1}$, I.Shamis ${ }^{1}$, S. Weitzman ${ }^{2}$, S. Rosen ${ }^{2}$, Z. V. I. Laron ${ }^{1}$ \\ ${ }^{1}$ Endocrinology and Diabetes Research Unit, WHO Collaborating Center for the Study of Diabetes in Youth, \\ Schneider Children's Medical Center, Tel Aviv University, Tel Aviv, Israel \\ ${ }^{2}$ Department of Epidemiology and Health Services Evaluation, Ben Gurion University of the Negev and Soroka University \\ Medical Center, Beer-Sheva, Israel
}

\section{Abstract}

Aims/hypothesis. The aim of this study was to examine the mortality rate of subjects with childhood-onset Type I (insulin-dependent) diabetes mellitus in Israel. Methods. The whole-country cohort of 1861 children and adolescents (0-17 years) with Type I diabetes, diagnosed between January 1965 and December 1993 in Israel, was analysed for mortality up to October 1996.

Results. A total of 37 deaths were identified with an ascertainment rate of $100 \%$. There was a significant $(p<0.001)$ excess mortality in the patients with Type I diabetes, the standard mortality ratio being three times higher than that of the general population. The causes of mortality were ketoacidosis $(n=8)$, infections $(n=8)$, chronic diabetes complications $(n=9)$, external causes $(n=6)$ and other $(n=6)$. Among the subjects who died, the prevalence of nephropathy, neuropathy and anaemia was higher in female than in male subjects. A total of 17 of the patients with diabetes who died had a central nervous disease (psychosis, mental retardation, epilepsy). There was a trend to lower mortality among the Arab cohort which did not reach statistical significance.

Conclusions/interpretation. Our data provide additional evidence that childhood-onset Type I diabetes carries an increased mortality risk when compared with the mortality risk of the non-diabetic population. [Diabetologia (2001) 44 [Suppl 3]: B 81-B 86]

Keywords Childhood Type I diabetes, mortality, population studies, ethnic distribution, diabetes in Israel.
The introduction of regional or whole-country registers of Type I diabetes has shown that the incidence of childhood diabetes is rapidly increasing in many parts of the world including Israel [1-9]. However, long-term follow-up surveys relating to the mortality rates of patients with childhood-onset Type I diabetes are rare [10-16].

In 1991 we reported on the mortality in a cohort of 614 Jewish Israeli patients with childhood-onset Type

Corresponding author: Prof. Z. V. I. Laron, Endocrinology and Diabetes Research Unit, Schneider Children's Medical Center, 14 Kaplan Street, Petah Tikva 49202, Israel

*This investigation is part of the thesis of T. Laron-Kenet in partial fulfilment of the requirements for the MD degree

Abbreviations: SMR, standard mortality ratio.
I diabetes diagnosed between the years 1965 and 1979 [17]. We have continued the whole-country registry of newly diagnosed Type I diabetic patients in Israel and report in this study on the mortality of the whole-country cohort of 1861 patients with Type I diabetes in Israel diagnosed under the age of 18 between the years 1965 and 1993 and belonging to several ethnic groups.

\section{Subjects and methods}

Definition of the study cohort. The population included in this study comprises the whole-country cohort of patients with childhood Type I diabetes (0-17 $11 / 12$ years - forthwith 0-17 years) resident in Israel and newly diagnosed between 1 January 1965 and 31 December 1993. It constitutes the Israel Registry of Type I childhood diabetes which is part of the Diabetes Epidemiology Research International (DERI) Study 
(1965 -1979) [18] and subsequently the EURODIAB ACE Project (1980-1993) [1]. The degree of ascertainment was estimated to be over $95 \%$.

Altogether seven patients with associated diseases such as Bloom's syndrome, cystic fibrosis, thalassaemia major, pancreatectomy, glucocorticoid-induced diabetes and Wolfram's syndrome were excluded from this study. The total number of patients with childhood Type I diabetes for the above 1965 to 1993 period was 1861 . During this period the Israeli population consisted of the following major ethnic groups: Ashkenazi Jews (European origin), non-Ashkenazi Jews (North African, Mediterranean, Middle-Eastern origin) approximately $40 \%$ each and Israeli Arabs (18\% of the total population).

The study was approved by the Hospital Ethical Committee and the legal offices of the Ministries of Health and Interior.

Determination of death and its cause. The death of patients was ascertained from the records of hospitals where the patients were treated or died. In addition, the survival status of the cohort up to 30th October 1996 was confirmed by submitting the official identification (ID) numbers of all the 1861 patients into the computerized register of the Interior Ministry which then checked these against the National Death Registry. Ascertainment of death was $100 \%$. All the medical charts and the death certificates as well as six available necropsy reports for the deceased patients were reviewed and the details of their medical history including diagnosis and course of Type I diabetes complications and cause of death were noted. In instances in which more than one cause of death was cited, the primary (underlying) cause was chosen by two independent physicians. In cases of disagreement a third reviewer was consulted.

Statistical analysis. Statistical analysis was done using the SPSS programme. The incidence of mortality was calculated using several methods:

The follow-up period for each patient was calculated from the date of diagnosis (date of first insulin injection) to the date either of death or the census (30 October 1996). Standardized mortality ratios (SMRS) were calculated per 5 years using the equations of Kilpatrick [19] and Hill [20] and compared with the age adjusted mortality rate in the general population of Israel provided by the Central Bureau of Statistics in the year 1996 [21]. A SMR of 1 denotes equal mortality ratio to the general population. The $95 \%$ CIs were calculated using Byar's approximation of Poisson's regression analysis [22]. Survival rates were calculated according to the Kaplan-Meier survival method [23], and the log-rank test was used to ascertain statistically significant differences between them.

Differences between means were calculated using the Student's $t$ test.

\section{Results}

The whole-country registry in Israel for Type I diabetes (0-17 years) between the years 1965 and 1993 was carried out by the Endocrinology and Diabetes Research Unit, Beilinson and Schneider Children's Medical Centres [9]. Out of 1861 newly diagnosed patients with Type I diabetes, 37 died before 30 October 1996. The duration of observation ranged from 1 to 32 years (mean $\pm \mathrm{SD}=14 \pm 8$ years) providing a total of 23877 person-years of follow-up. The differences
Table 1. Demographic characteristics of the diabetic cohort studied

\begin{tabular}{lcc}
\hline & \multicolumn{2}{c}{$\begin{array}{l}\text { Population with childhood } \\
\text { diabetes (1965-1993) }\end{array}$} \\
\cline { 2 - 3 } & Cohort Studied & Deceased \\
\hline Number (\%) & $1861(100)$ & $37(100)$ \\
Sex: Male & $921(49)$ & $17(1.8)$ \\
Females & $940(51)$ & $20(2.1)$ \\
Ethnic Origin: & & \\
Ashkenazi Jews & $615(33)$ & $17(2.8)$ \\
Non-Ashkenazi Jews & $995(54)$ & $17(1.7)$ \\
Arabs & $157(8)$ & $2(1.3)$ \\
Unknown & $94(5)$ & 1 \\
Age at Diagnosis (Years) & & \\
0-11 & 1013 & $20(2)$ \\
12-18 & 848 & $17(2)$ \\
\hline
\end{tabular}

in mortality rates between the groups were not statistically significant (Arabs vs Ashkenazi Jews, $p=0.3$; Arabs vs non-Ashkenazi Jews, $p=0.7$; Ashkenazi vs non-Ashkenazi Jews, $p=0.2$ ) (Table 1 ). The mean age at diagnosis was $10.6 \pm 4.4$ years.

Mortality according to age at diagnosis, duration of disease, and sex. No difference in the overall mortality rate was seen when dividing the subjects into groups of under 12 and over 12 years of age. Out of 1013 patients diagnosed before 12 years of age, $20(2.0 \%)$ had died. Out of 848 patients diagnosed between 12 to 17 years of age, $17(2 \%)$ had died (Table 1$)$. However the death of the patients diagnosed before 12 years of age occurred at a younger age than those diagnosed at 12 years of age or later (log-rank $=5.8 ; p=0.016$ ). There was no difference in mortality rate according to duration of disease between patients diagnosed before 12 years of age and those diagnosed later (log-rank $p=0.89)$. Notably no patient died at or shortly after diagnosis, nor did any patient die before 5 years of age.

Out of 940 female patients, $20(2.1 \%)$ died, and out of 921 male patients, 17 (1.8\%) died (Table 1), thus there is no difference in the mortality pattern between sexes.

In both studies there is a drop in the mortality rate in the second 6 years of duration compared with the first 6 years, with an increasing rate again in the third 6 -year period. In males, the progressive increase in mortality rate with duration of disease is significant $(p<0.004)$.

Causes of death. The most frequent causes of death of the 37 patients with childhood-onset Type I diabetes were ketoacidosis $(21.6 \%)$ and infections $(21.6 \%)$ (Table 2). Out of the 8 patients who died of ketoacidosis, there were 5 females and 3 males between 8 and 37 years of age. One patient died 10 months after diagnosis, two between 7 and 14 years of disease duration. The remaining died between 14 and 19 years 
Table 2. Cause of death of 37 patients with childhood-onset (0-17 years) Type I diabetes in Israel (January 1965-October 1996)

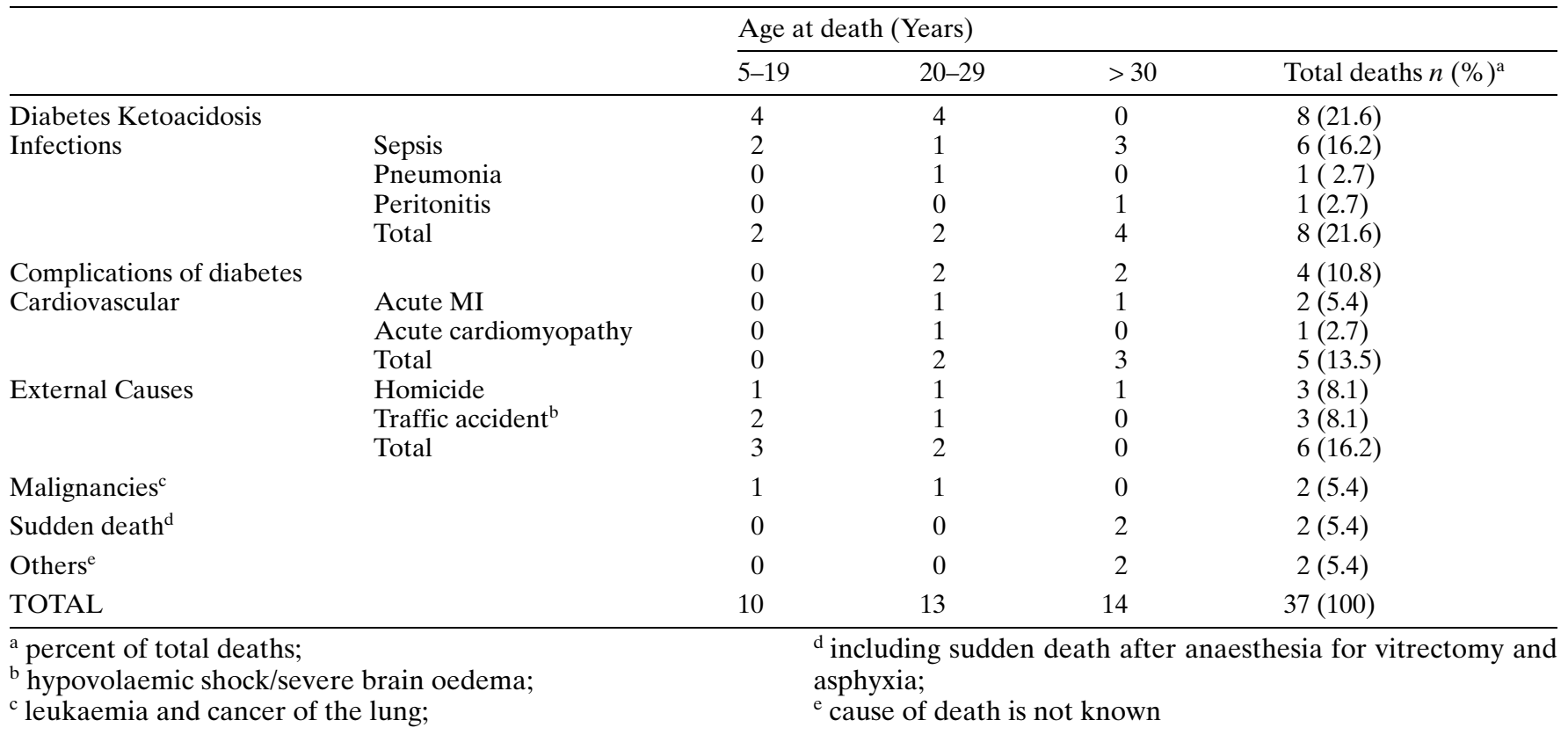

Table 3. Chronic diabetes complications at time of death of 37 patients with childhood-onset Type I diabetes

\begin{tabular}{|c|c|c|c|c|c|c|c|}
\hline \multirow[b]{2}{*}{$\begin{array}{l}\text { Diabetes complica- } \\
\text { tions }\end{array}$} & & \multicolumn{3}{|c|}{ Age at death (Years) $n(\%)$} & \multirow{2}{*}{$\begin{array}{l}\text { Total deaths } \\
n(\%)\end{array}$} & \multirow{2}{*}{$\begin{array}{l}\text { Females } \\
n\end{array}$} & \multirow{2}{*}{$\begin{array}{l}\text { Males } \\
n\end{array}$} \\
\hline & & $0-19^{\mathrm{a}}$ & $20-29$ & $>30$ & & & \\
\hline Nephropathy & & $2(20)$ & $4(30.7)$ & $10(71.4)$ & $16(43.2)$ & 10 & 6 \\
\hline Hypertension & & $2(20)$ & $2(15.3)$ & $7(50)$ & $11(30.0)$ & 5 & 6 \\
\hline Cardiovascular & $\begin{array}{l}\text { Acute MI \& ischaemic } \\
\text { heart disease } \\
\text { Cardiac insufficiency } \\
\text { Others }\end{array}$ & $\begin{array}{l}0 \\
0 \\
0\end{array}$ & $\begin{array}{l}1(7.7) \\
1(7.7) \\
1(7.7)\end{array}$ & $\begin{array}{l}4(28.6) \\
5(3.6) \\
1(7.1)\end{array}$ & $\begin{array}{l}5(13.5) \\
6(16.2) \\
2(5.4)\end{array}$ & $\begin{array}{l}1 \\
6 \\
2\end{array}$ & 4 \\
\hline Neuropathy & & $1(10)$ & $1(7.7)$ & $8(57.1)$ & $10(27.0)$ & 6 & 4 \\
\hline Anaemia & & 0 & $4(30.8)$ & $4(28.6)$ & $8(21.6)$ & 7 & 1 \\
\hline
\end{tabular}

a the youngest age at death was $5 ;{ }^{b}$ including 1 patient with each of cardiovascular angiopathy and acute cardiomyopathy; $\mathrm{MI}=$ myocardial carfarction

disease duration and all of these had suffered from previous hypoglycaemic and hyperglycaemic episodes.

Of the patients who had chronic diabetes complications at the time of their death, approximately half had retinopathy and/or nephropathy, and one third had hypertension (Table 3 ). Notably female patients had more neuropathy, acute myocardial infarction and ischaemic heart disease, nephropathy and almost all had severe anaemia, most probably related to nephropathy. In summary, 33 out of the 37 patients who died had one or more chronic diabetes complications, 2 had none and no information was available on the remaining 2 patients. Altogether 3 patients with a disease duration of over 30 years had undergone lower limb amputation.
Of the additional disorders diagnosed in the patients with diabetes, $45.9 \%$ were connected with the central nervous system disease (Table 4). A total of $21.5 \%$ of the patients had an associated endocrine disease, mostly of autoimmune origin.

Standardized mortality ratio (SMR). The overall SMR in the diabetes cohort with childhood-onset Type I diabetes in Israel is significantly higher for the whole group than that of the Israeli mortality statistics, especially in the younger age groups (Table 5). After 34 years of age, we found no difference in SMR between patients with diabetes and the general population. 
Table 4. Additional diseases diagnosed in the 37 patients with childhood-onset Type I diabetes who died

\begin{tabular}{lllll}
\hline & \multicolumn{3}{l}{ Age at death (Years) } & \multirow{2}{*}{$\begin{array}{l}\text { Total }(\%) \\
\text { deaths }\end{array}$} \\
\cline { 2 - 4 } Disease n (\%) & $0-19^{\mathrm{a}}$ & $20-29$ & $>30$ & $n$ \\
\hline Mental disorder $^{\mathrm{b}}$ & 2 & 5 & 3 & $10(27.0)$ \\
Mental retardation $^{\text {Epilepsy }}$ & 2 & 2 & 0 & $4(10.8)$ \\
Endocrine $^{\mathrm{c}}$ & 1 & 2 & 0 & $3(8.1)$ \\
Others $^{\mathrm{d}}$ & 1 & 3 & 4 & $8(21.6)$ \\
\hline
\end{tabular}

${ }^{\mathrm{a}}$ the youngest age at death was $5 ;{ }^{\mathrm{b}}$ including major depression (four patients), personality disorders, anorexia nervosa and undefined psychopathology. All had been treated previously in psychiatric clinics, some had been hospitalized; ${ }^{\mathrm{c}}$ Hashimoto thyroiditis, hypothyroidism, osteoporosis, diabetes insipidus and autoimmune endocrine polyglandular disease; deafness, poliomyelitis, acute lymphocytic leukemia and chronic obstructive pulmonary disease

\section{Discussion}

This study is one of the very few examining mortality rates during long-term follow-up of a large cohort of childhood-onset Type I diabetes in a whole-country population.

A study carried out in Estonia reviewed the survival of 340 children (0-14 years of age) diagnosed between 1980 and 1989 [14]. Another population-based cohort of 1185 children (0-14 years old) was reviewed in Austria between the years 1979 and 1990 [7]. The largest cohort studied was in Finland (5162 patients) followed between 1965 to 1985 [18]. Few other studies are based on regional population registers $[13,15$, 16].

Distinct from other studies we were able to compare the mortality rate between various ethnic groups residing in the same small country and differing in the incidence of Type I diabetes [9].

Out of the 1861 patients followed for 23877 person-years duration of diabetes, 37 died. Compared with studies available from other countries, the over-

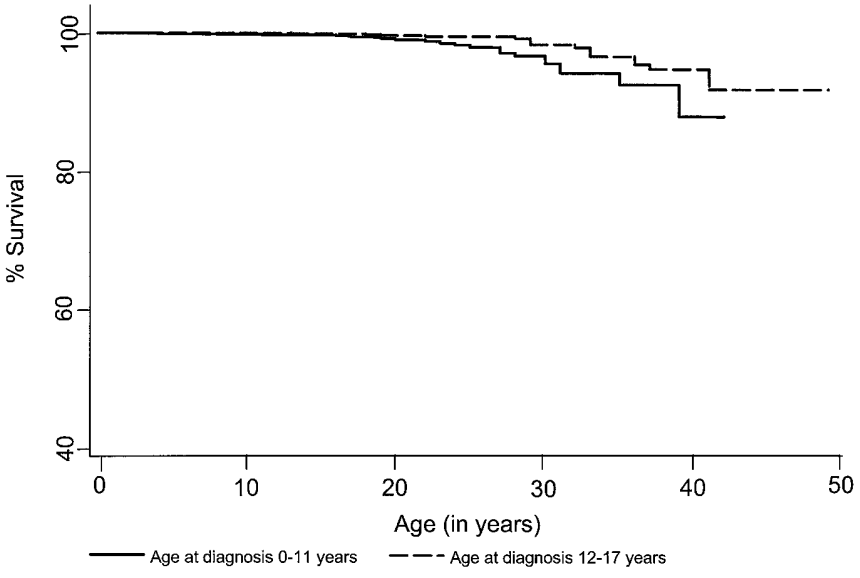

Fig. 1. Cumulative survival curve of 1861 patients with childhood-onset (0-17 years) Type I diabetes diagnosed in Israel between 1965 and 1993

all SMR rate in Israel is low both for the length of the follow-up period, i.e. 32 years in our study (with a median of 12.0 years) and for the age of the patients. The SMR seems close to that found in the Finnish population followed for a similar length of time and with a higher incidence of diabetes $[4,16]$. Overall, the SMR of Type I childhood diabetes patients in Israel is three times higher than the general Israeli population. This excess mortality, compared to the general Israeli population, is particularly evident between 5-19 years of age, when it decreases, but is still significantly higher than the general population until 34 years of age. After 34 years of age, no differences in mortality rates were found between the Type I diabetic patients and the general population.

The number of deaths were distributed equally between both sexes and between the Ashkenazi and non-Ashkenazi Jews. The Arabs who represent $18 \%$ of the total population of Israel, had only $5 \%$ of the deaths in this group of diabetic patients. The Arabs also have the lowest incidence of Type I diabetes

Table 5. Standardized mortality ratio (SMR) in a cohort of 1861 subjects with childhood-onset Type I diabetes (diagnosed 1965-1993)

\begin{tabular}{|c|c|c|c|c|c|c|c|c|}
\hline \multirow[b]{2}{*}{$\begin{array}{l}\text { Age group } \\
\text { (Years) }\end{array}$} & \multicolumn{3}{|c|}{ Israeli mortality statistics 1996} & \multicolumn{5}{|c|}{ Type I diabetic cohort } \\
\hline & $\begin{array}{l}\text { Number } \\
\text { of deaths }\end{array}$ & Population & $\begin{array}{l}\text { Rate } \\
\text { (1000/year) }\end{array}$ & $\begin{array}{l}\text { Number } \\
\text { of deaths }\end{array}$ & Person-years & $\begin{array}{l}\text { Expected number } \\
\text { of deaths }\end{array}$ & SMR & $95 \%-\mathrm{CI}$ \\
\hline $5-9$ & 52 & 547800 & 0.0949 & 2 & 303 & 0.0288 & 69.54 & $8.41-251$ \\
\hline 10-14 & 62 & 534800 & 0.1159 & 2 & 1357 & 0.1573 & 12.71 & $1.54-45.89$ \\
\hline $15-19$ & 139 & 512600 & 0.2712 & 6 & 2476 & 0.6714 & 8.94 & $3.28-19.48$ \\
\hline $20-24$ & 241 & 490800 & 0.4910 & 5 & 4258 & 2.0908 & 2.39 & $0.77-5.57$ \\
\hline $35-39$ & 234 & 364900 & 0.6413 & 3 & 3649 & 2.3400 & 1.28 & $0.26-3.74$ \\
\hline $40-44$ & 299 & 361400 & 0.8273 & 3 & 1787 & 1.4785 & 2.03 & $0.42-5.93$ \\
\hline $45-49$ & 463 & 337600 & 1.3714 & 0 & 653 & 0.8956 & 0.00 & 0 \\
\hline Total & 2352 & 4516100 & 0.5208 & 37 & 23877 & 12.4352 & 2.98 & $2.1-4.09$ \\
\hline
\end{tabular}


among the various ethnic groups in Israel $(8 \%$ of our cohort) [9]. A total of 10 patients died between 15 and 24 years of age, and 16 between 25 and 34 years of age. The youngest patient died aged 5 years. Duration of disease was statistically significantly related to death in the male patients only. Of note is that during the second 6 years of disease there was a decrease in mortality in both sexes compared with the first 6 or subsequent years of disease.

Although diagnosis before 12 years of age was associated with a younger age at death, the survival analysis by duration of disease did not show a statistically significant difference between the groups according to age at diagnosis (before and after 12 years of age). Of special note is that there was no death at or shortly after the onset of disease, as reported from other countries [7, 8, 13, 14, 24]. This is probably due to an awareness among the population of the early symptoms of diabetes through long standing population-oriented educational programmes [25] and easily availabile medical services.

A total of 25 (possibly 27) out of 37 causes of death $(\sim 73 \%)$ can be ascribed to being directly related to the diagnosis of diabetes. The majority were due to diabetic ketoacidosis, infections or complications, which are partly preventable by improved metabolic control [26]. Several findings in our study seem of special interest: 17 (46\%) of our deceased patients had some kind of disorder of the central nervous system (Table 4). This is not mentioned in other surveys, and certainly plays a role in the motivation to maintain good metabolic control. Whether the sudden deaths belong to the "dead in bed" syndrome $[8,27]$ or were suicides is not clear. The traffic accidents were passive according to the information obtained.

Despite an equal distribution of deaths between the two sexes, the prevalence of nephropathy, neuropathy and anaemia was higher in the female than in the male patients, whereas cardiac disease occurred almost exclusively in males.

In conclusion, even with a relatively low mortality rate compared with other countries, a well-developed multidisciplinary team approach and a National Insurance Medical System, mortality rates in childhood-onset Type I diabetes patients in Israel remain higher than in the general population.

Acknowledgements. This study was supported in part by a grant to Z. Laron from Mr. E. Kaufman, E.F.D., Israel

\section{References}

1. Green A, Gale EAM, Patterson GC for the Eurodiab ACE Study Group (1992) Incidence of childhood-onset insulindependent diabetes mellitus; the Eurodiab ACE study. Lancet 339: 905-909
2. Bingley PJ, Gale EAM (1989) Rising incidence of IDDM in Europe. Diabetes Care 23: P289-P295

3. Joner G, Søvik O (1989) Increasing incidence of diabetes mellitus in Norwegian children 0-14 years of age 1973-1982. Diabetologia 32: 79-83

4. Tuomilehto-Wolf E, Akerblom HK (1991) Increasing trend in Type I (insulin-dependent) diabetes mellitus in childhood in Finland. Diabetologia 34: 282-287

5. Soltesz G, Madacsy L, Befeki D, Danko J (1990) Hungarian Childhood Diabetes Epidemiology Group: Rising incidence of type 1 diabetes in Hungarian children. Diabet Med 7: 111-114

6. Drykoningen CEM, Mulder AL, Vaandrager FJ, LaPorte RE, Bruining GJ (1992) The incidence of male childhood Type I (insulin-dependent) diabetes mellitus is rising rapidly in The Netherlands. Diabetologia 35: 139-142

7. Schober E, Schneider U, Waldhor T, Tuomilehto J, the Austrian Diabetes Incidence Study Group (1995) Increasing incidence of IDDM in Austrian children; a nationwide study 1979-1993. Diabetes Care 18: 1280-1283

8. Sartor G, Dahlquist G (1995) Short-term mortality in childhood onset insulin-dependent diabetes mellitus: a high frequency of unexpected deaths in bed. Diabet Med 12: 607-611

9. Shamis I, Gordon O, Albag Y, Goldsand G, Laron Z (1997) Ethnic differences in the incidence of childhood IDDM in Israel (1965-1993): Marked increase since 1985, especially in Yemenite Jews. Diabetes Care 20: 504-508

10. Lestradet H, Papoz L, Hellouin de Menibus C et al. (1981) Long-term study of mortality and vascular complications of juvenile onset (type I) diabetes. Diabetes 30: 175-179

11. Dorman JS, LaPorte RE, Kuller LH et al. (1984) The Pittsburgh insulin-dependent diabetes mellitus (IDDM) morbidity and mortality study. Mortality results. Diabetes 33: 271-276

12. The Diabetes Epidemiology Research International (DERI) Study (1995) International analysis of insulin-dependent diabetes mellitus mortality: a preventable mortality perspective. Am J Epidemiol 142: 612-618

13. McNally PG, Raymond NT, Burden ML et al. (1995) Trends in mortality of childhood-onset insulin-dependent diabetes mellitus in Leicestershire: 1940-1991. Diabetic Med 12: 961-966

14. Podar T, Solntsev A, Rahu M, Leinsalu M, Tuomilehto J, LaPorte RE (1996) Mortality of childhood-onset IDDM patients in Estonia. Diabetologia 30: 1238-1239

15. Warner DP, McKinney PA, Law GR, Bodansky HJ (1998) Mortality and diabetes from a population based register in Yorkshire 1978-93. Arch Dis Child 78: 435-438

16. Asao K, Sarti C, Matsushima M, Tajima N, for the DERI Mortality Study Group (1999) Mortality of patients with insulin-dependent diabetes mellitus in Japan compared with those in Finland. Diabetes 48 [Suppl 1]: A43 (Abstract).

17. Modan M, Karp M, Bauman B, Gordon O, Danon YL, Laron Z (1991) Mortality in Israeli Jewish patients with Type I (insulin-dependent) diabetes mellitus diagnosed prior to 18 years of age: a population based study. Diabetologia 34: $515-520$

18. Diabetes Epidemiology Research International Group (1988) Geographic patterns of childhood insulin-dependent diabetes. Diabetes 37: 1113-1119

19. Kilpatrick SJ (1962) Occupational mortality indices. Popul Studies 16: 175

20. Hill AB (1971) Principles of medical statistics. $9^{\text {th }}$ edn. Oxford University Press, New York

21. Statistical abstracts of Israel no. 47 (1996) Central Bureau of Statistics, Government Press, Jerusalem 
22. Breslow NE, Day NE (1987) Statistical methods in cancer research. Vol 2. The design and analysis of cohort studies. IARC, Lyon

23. Kaplan EL, Meier P (1958) Nonparametric estimation from incomplete observations. J Am Statist Assoc 53: 457-481

24. Hirasing RA, Böhm FJ, Reeser HM, Oei YB, Vaadrager GJ, Verloove-Vanhorick SP (1995) Onset mortality of type I diabetes in 0 to 19-year-old children in the Netherlands, 1988-1990. Acta Paediatr 84: 1197-1198
25. Laron Z, Galatzer A, Amir S, Gil R, Karp M, Mimouni M (1979) A multidisciplinary comprehensive, ambulatory treatment scheme for diabetes mellitus in children. Diabetes Care 2: 342-348

26. The Diabetes Control and Complications Research Group (1993) The effect of intensive treatment of diabetes on the development and progression of long- term complications in IDDM. N Engl J Med 329: 977-986

27. Thordarson T, Sovik O (1995) Dead in bed syndrome in young diabetic patients in Norway. Diabet Med 12: 782-787 